https://doi.org/10.24201/aap.2020.303

\title{
CHINA Y HONG KONG
}

\author{
FRANCISCO JAVIER HARO NAVEJAS \\ ORCID: https://orcid.org/0000-0002-1061-2508 \\ Universidad de Colima \\ ROMER CORNEJO BUSTAMANTE \\ ORCID: https://orcid.org/0000-0002-6634-491X \\ El Colegio de México, A. C.
}

Para China, 2019 ha representado un periodo importante para repensar sus perspectivas. En el ámbito político, en la primavera de 2018, la decisión de la Asamblea Popular Nacional (APN) de hacer indefinida la reelección del presidente, así como la continuación de la lucha contra la corrupción, mantiene inquietos a algunos sectores dentro del Partido Comunista. No obstante, el presidente Xi Jinping se ha mantenido como la figura dominante de la política china y cuenta con la lealtad de la mayoría de todas las facciones del partido gobernante, el ejército y la élite empresarial. Xi ha demostrado tener una visión política clara y ha promovido ambiciosos proyectos nacionales, entre ellos, acabar con la pobreza del país en el corto plazo, además de una iniciativa internacional, como la Nueva Ruta de la Seda, que posicionaría al país como potencia mundial indiscutible en el mediano plazo, lo que a su vez ha estado acompañado de un enorme esfuerzo por mostrar una imagen benigna hacia el exterior. Quizá podamos medir la eficacia de estas medidas a través de la reacción de los Estados Unidos, que han revitalizado su campaña sobre la amenaza china, particularmente en América Latina, así como la reciente de desconfianza de los miembros de la Organización del Tratado del Atlántico Norte (OTAN).

D.R. @ 2020. Anuario Asia Pacífico

Licencia Creative Commons Atribución-NoComercial-SinDerivar (CC BY-NC-ND) 4.0 Internacional 
La celebración de los 70 años de la fundación de la República Popular bajo el mando del Partido Comunista fue una buena oportunidad para que el gobierno exhibiera ante su población y frente al exterior su poderío militar, realizando un despliegue de nuevos misiles, lanzadores de cohetes múltiples, bombarderos más sofisticados, tanques ligeros para todo terreno, vehículos autónomos para uso aéreo y submarino, drones de reconocimiento hipersónicos de largo alcance y otros instrumentos con los que cuenta ahora el ejército para la defensa del país. Gran parte de este despliegue estuvo dirigido a la población, para hacerla consciente del poder de su país y alimentar el nacionalismo. También fue un mensaje para responder a las amenazas de los Estados Unidos en el Mar del Sur de China, a las revueltas en Hong Kong y a las tendencias independentistas de Taiwán. En síntesis, fue un mensaje destinado a cualquier intento de amenaza a su concepto de soberanía territorial. No obstante, los Estados Unidos siguen superando la fuerza militar de China. La fuerza militar de Washington cuenta con 13398 naves aéreas de diversos tipos, mientras China tiene 3187 ; asimismo, los Estados Unidos disponen de 2141900 soldados, mientras China tiene 2693 000. Sin embargo, ambos tienen la capacidad nuclear para la destrucción mutua (Panayiotides, 2019).

El gobierno de China tiene aún muchos problemas por resolver. Sobresalen el envejecimiento de la población, el desequilibro de género por la preferencia de hijos varones y la severa desigualdad de ingresos que ha traído, como en muchos otros países, el liberalismo económico. Asimismo, el gobierno aplica una férrea política a la disidencia musulmana en Xinjiang, una región estratégica por sus recursos y posición geográfica. También enfrenta la permanencia de la corrupción, las altas deudas de los gobiernos locales, el descenso del ritmo de crecimiento por la crisis mundial y la guerra comercial con los Estados Unidos, así como la degradación ambiental creciente por el consumismo desenfrenado, que requerirán una respuesta eficaz en los próximos años.

No son problemas desconocidos para los gobernantes de China, pero su enfrentamiento se ha visto rezagado en función del fortalecimiento económico y militar que posicione al país como potencia en el ámbito internacional. 


\section{DESEMPEÑO ECONÓMICO}

A pesar de la recesión económica mundial y de la guerra económica desatada por el gobierno de los Estados Unidos, la prensa oficial china informa de incrementos importantes en algunos sectores de su economía gracias al mercado interno y a otros factores (Xinhua, 2019). El cuarto censo económico nacional mostró que China contaba con 21.79 millones de entidades legales dedicadas a la industria secundaria y terciaria: a finales de 2018, 100.7\% más que al término de 2013, cuando se llevó a cabo el anterior censo económico.

- El país poseía 18.57 millones de empresas en industrias secundaria y terciaria al finalizar 2018, de las cuales $98.8 \%$ era de capital de la parte continental de China, $0.6 \%$ contaban con inversiones de Hong Kong, Macao y Taiwán, y otro $0.6 \%$ con fondos extranjeros.

A finales de 2018:

- Los sectores secundario y terciario emplearon un total de 383.24 millones de personas: 7.6\% más respecto al cierre de 2013 .

- El volumen de capital comercial de las industrias secundaria y terciaria alcanzó 914.2 billones de yuanes (130.38 billones de dólares). El sector secundario, que incluye las empresas industriales y de construcción, representó 19\% de los activos totales, mientras que el terciario, o sector servicios, ocupó el $81 \%$ restante.

- China tenía 66214 compañías dedicadas a las industrias emergentes estratégicas, con ingresos anuales superiores a 20 millones de yuanes cada una: 17.7\% del número total de firmas industriales que se encuentran por encima del tamaño designado.

- Había 33573 compañías manufactureras de alta tecnología que se encuentran por encima del tamaño designado, lo que marca un incremento de $24.8 \%$ respecto al cierre de 2013.

- Los gastos en investigación y desarrollo de dichas empresas totalizaron 355910 millones de yuanes, un aumento de 75\% en comparación con 2013 (National Bureau of Statistics of China, 2019). 
Por lo anterior, China es hoy la segunda economía global, el mayor exportador y el mayor poseedor de reservas del mundo. Si bien desde la crisis global de 2009 China no ha recuperado su crecimiento de dos dígitos, lo que reveló la importancia de estimular su mercado interno, ha mantenido uno de los mayores crecimientos del PIB del mundo, por encima del $6 \%$ anual.

Nuevos sectores como el comercio y los servicios por internet han revitalizado mucho la economía, agilizando las transacciones, lo que se expresa desde el comercio minoritario cotidiano hasta los sectores orientados a la exportación. No obstante, se espera que a fines de 2019 se manifiesten las consecuencias de la guerra comercial con los Estados Unidos en las cuentas del país, aunque los cálculos no llegan a una afectación del 1\% del PIB. Asimismo, se espera que la inflación siga estable, rondando el $2.5 \%$.

Un asunto preocupante para los economistas chinos es la deuda pública, pues los números reales suelen ser superiores a los revelados por las entidades gubernamentales. Entidades internacionales como Forbes han estimado que la relación de la deuda con el PIB es de $300 \%$, lo cual puede resultar exagerado. Aunque el nivel de crédito de China es alto, comparado con otros países, la deuda corporativa ha llegado a niveles de $165 \%$ del PIB, pero la deuda de las familias apenas se ha elevado a 15\% del PIB, lo cual es relativamente bajo. Durante 2019 el gobierno del presidente Xi ha puesto gran atención a la deuda de las empresas estatales, colocándola como una prioridad. No obstante, los problemas comerciales con Estados Unidos, entre otros, han llevado a las autoridades a introducir medidas monetarias más flexibles, como estimular a los bancos a facilitar créditos a las empresas más pequeñas.

El gobierno continuó en 2019 su política de contracción presupuestaria que se calcula en una reducción de más del 4\%, aunque todavía las cifras oficiales no se han dado a conocer. Al mismo tiempo, China mantiene todavía grandes reservas en monedas extranjeras, calculadas en más de tres billones de dólares, lo cual, sumado a un excedente en cuenta corriente de más de 200000 millones de dólares, constituye un escudo protector para la volatilidad de la economía exterior.

Uno de los más grandes retos sociales políticos y económicos de China sigue siendo la gran diferencia entre las condiciones de vida del campo y las ciudades, entre las zonas 
urbanas del interior y las zonas costeras, así como entre las clases medias urbanas y las clases menos favorecidas. Estas diferencias preocupan a las autoridades chinas y a los empresarios. Si bien la pobreza ha disminuido, el desempleo permanece estable, alrededor del 4\%; según fuentes oficiales, ésta es difícil de abatir debido a la economía digital y a la manera en que el empresariado intermediario conduce sus negocios, de manera que cerca de 43 millones de personas continúan viviendo con menos de 1 dólar al día, la línea de pobreza establecida por el gobierno, y están claramente en la mira de Xi Jinping como un problema a superar durante los próximos años.

CUADRO 1. Indicadores básicos de la economía de China, 2016-2019

(\% y USD miles de millones)

\begin{tabular}{|l|c|c|c|c|c|}
\hline Principales indicadores & 2016 & 2017 & $2018(e)$ & $2019(e)$ & $2020(e)$ \\
\hline PIB (miles de millones de USD) & 11221.84 & $12014.61 \mathrm{e}$ & 13457.27 & 14172.20 & 15461.96 \\
\hline $\begin{array}{l}\text { PIB (cambio porcentual anual a precios } \\
\text { constantes) }\end{array}$ & 6.7 & $6.9(\mathrm{e})$ & 6.6 & 6.2 & 6.2 \\
\hline PIB per cápita (USD) & 8116 & $8643(\mathrm{e})$ & 9633 & 10099 & 10971 \\
\hline Balance general del gobierno (\% del PIB) & -3.6 & -4.0 & -4.2 & -4.5 & -4.4 \\
\hline Deuda bruta general del gobierno (\% del PIB) & 44.2 & 47.0 & 50.1 & 53.9 & 57.1 \\
\hline Tasa de inflación (\%) & 2.0 & 1.6 & 2.2 & 2.4 & 2.7 \\
\hline Tasa de desempleo (\% de la fuerza laboral) & 4.0 & 3.9 & 4.0 & 4.0 & 4.0 \\
\hline Cuenta corriente (miles de millones USD) & 202.20 & 164.89 & 97.55 & 98.43 & 107.30 \\
\hline Cuenta corriente como porcentaje del PIB & 1.8 & 1.4 & 0.7 & 0.7 & 0.7 \\
\hline
\end{tabular}

FUENTE: IMF, World Economic Outlook Database, octubre de 2018. (e) datos estimados.

La economía de China es altamente diversificada, con predominio de los sectores manufactureros y agrícolas. Por su tamaño, obviamente, es uno de los más grandes productores y consumidores de productos agrícolas del mundo. Se estima que el sector agrícola emplea $16 \%$ de la población activa y aporta $8 \%$ del PIB, a pesar de que apenas 15\% o menos de su territorio es cultivable. El país se ha convertido en un productor líder de cereales, arroz, algodón, papas y té. Asimismo, domina la crianza de ovejas y cerdo, y es el más grande productor de pescados del mundo. Por otro lado, China tiene grandes reservas de recursos naturales, particularmente carbón, que es empleado en dos tercios del consumo de energía del país, lo cual está disminuyendo en función de las medidas anticontaminación; 
además, es líder en la producción de zinc, estaño, hierro, oro, fosfatos y titanio, sus reservas de gas y petróleo son significativas, lo que la convierte en el quinto mayor productor de petróleo del mundo, con 3.8 millones de barriles al año.

La industria contribuye con más de $40 \%$ del PIB y emplea a casi $27 \%$ de la población. Es prácticamente el destino más importante para el outsourcing de la manufactura global por sus salarios competitivos y la estabilidad política. Más de la mitad de sus manufacturas son fabricadas por compañías que tienen diversas formas de participación extranjera. Su parte en el valor agregado de este sector varía según la industria: más de $60 \%$ en los electrónicos y cerca de $20 \%$ en la mayoría de bienes de producción. Es importante destacar que el sector estatal contribuye con $40 \%$ del PIB. La participación del sector servicios es cercana a 52\% del PIB y emplea aproximadamente $56 \%$ de la mano de obra.

Este sector no ha crecido a todo su potencial a causa de los monopolios y las regulaciones restrictivas; el Estado se ha enfocado más en las manufacturas para la exportación debido a lo que representan para el empleo, por lo que existen algunas barreras para la inversión. No obstante, este año el gobierno ha estado estimulando el sector servicios, especialmente en finanzas, logística, educación, salud y tiene como objetivo convertirse en el mayor exportador de transporte, turismo e insumos para la construcción.

CUADRO 2. Actividades por sector, 2019 (\%)

\begin{tabular}{|l|c|c|c|}
\hline \multicolumn{1}{|c|}{ Actividades económicas por sector } & Agricultura & Industria & Servicios \\
\hline Empleo por sector (\% del empleo total) & 16.4 & 26.3 & 55.9 \\
\hline Valor agregado (\% del PIB) & 7.9 & 40.5 & 51.6 \\
\hline Valor agregado (\% de cambio anual) & 3.9 & 6.1 & 7.8 \\
\hline
\end{tabular}

FUENTE: Banco Mundial. Datos recientes.

Según estimaciones recientes, las reservas de divisas de China cayeron de $\$ 9000$ millones de dólares en noviembre a \$3 096 mil millones, según mostraron los datos del Banco Central el 7 de diciembre de 2019. A pesar de la desaceleración económica mundial y los efectos de la guerra comercial desatada por los Estados Unidos, las reservas de China han aumentado gradualmente durante 2019, gracias a los estrictos controles sobre el capital y la llegada de inversiones extranjeras. Los cambios en los niveles de reserva de los últimos meses 
se deben en gran medida a las fluctuaciones de los tipos de cambio globales y al valor de los activos que posee China en el extranjero, a los cuales el yuan no ha sido inmune; después de caer bruscamente en el verano, subió en los tres meses siguientes y de nuevo ha caído a principios de diciembre, previéndose que los nuevos aranceles a los productos chinos entrarán en vigor el día 15 de ese mes. A pesar de esta situación, muchos analistas opinan que las salidas de capital han sido modestas en comparación con la recesión de 2015 y 2016, cuando fueron consumidos aproximadamente 1000 millones de dólares de las reservas que respaldaban al yuan. En los últimos meses el Banco Central de China ha comenzado a recortar lentamente las tasas de interés y se esperan más reducciones en los próximos trimestres para evitar una desaceleración más aguda (CNBC, 2019).

\section{POLÍTICA EXTERIOR}

Una de las tareas más complicadas que ha tenido el gobierno chino, sobre todo a partir de mayo de 1989, es revertir las percepciones negativas que existen en el mundo respecto a sus acciones. Las personas perciben a China de maneras que no siempre se pueden alinear a lo que las élites piensan y utilizan para negociar con Beijing. El año pasado estuvo plagado de problemas de percepción, relacionados con seguridad, turismo e intercambios educativos, principalmente.

De acuerdo con una encuesta realizada en 34 países (Silver, Devlin y Huang, 2019), una mediana de $41 \%$ tiene una opinión desfavorable respecto a China. No existe siempre una relación causal o correspondencia entre lo que opinaron los encuestados y las acciones de su gobierno. Aunque sí son significativos los casos de Japón, donde 85\% tiene una opinión desfavorable. Mientras que en Suecia es 70\%, en Canadá 67\%, y en los Estados Unidos 60\%. China y Japón viven en constantes roces mediáticos, los cuales no necesariamente se reflejan en las negociaciones, con la gran excepción de la disputa por islas e islotes en el Mar del Sur de China. Los suecos tienen conflicto con los chinos por casos de derechos humanos, en tanto que Beijing ha llegado a alertar a sus ciudadanos de no viajar a Suecia. La percepción de los canadienses tiene que ver con todo lo que gira alrededor de Huawei, cuyo pleito nos les corresponde. Con los Estados Unidos las razones sobran. En este campo deberían entrar Corea del Sur con 63\% de opinión desfavorable, y Australia con 57\%. Durante 2019 en este 
país hubo más roces con los chinos, y destacan los impactos mediáticos como los enfrentamientos físicos entre estudiantes del continente y de Hong Kong, también presentes en Canadá, además del asunto de un supuesto espía que pidió asilo.

Tres casos latinoamericanos sobresalen: Brasil, México y Argentina, donde los porcentajes han sido favorables: $51 \%, 50 \%$ y $47 \%$, respectivamente. El gobierno chino ha dedicado gran atención a Asia del Oeste, y los resultados obtenidos en Líbano e Israel podrían ser una muestra de ello. En el primero, 68\% fue favorable, mientras que en el segundo fue de 66\%. En el mismo tenor está África, donde los porcentajes son positivos, entre $70 \%$ de Kenia, y $46 \%$ de África del Sur. En Rusia fue 71\%, el más alto de la mediana.

Durante 2019, las relaciones entre los chinos y sus pares fueron más complejas que las simples percepciones.

\section{Estados Unidos}

En abril de 2017, aparentemente, Washington y Beijing se preparaban para reorganizar y relanzar sus relaciones bilaterales mediante un acuerdo comercial que cambiaría el statu quo e impediría a los chinos beneficiarse unilateralmente, según señaló Donald Trump en su campaña electoral. Además de buscar revertir el déficit comercial, se esperaba acceder a mercados financieros, energía y agricultura, principalmente. Los meses han pasado y ninguna de las partes está dispuesta a negociar respecto a lo sustancial. Una y otra vez se cancelan las reuniones. El conflicto escala: apoyo estadounidense a las protestas en Hong Kong, persecución a las ONG estadounidenses en China y bloqueo a naves de ese país que solían atracar en Hong Kong.

Todo el año hubo momentos de acercamiento; como en enero, cuando se acordó una tregua de tres meses, a la que siguieron enfrentamientos cada vez más virulentos provocados desde la Casa Blanca. Trump pospuso, ocasionalmente, la aplicación de tarifas, China hizo otro tanto con autopartes y suspendió la exportación de todo tipo de fetanyl sintético. Por momentos impusieron tarifas arancelarias, en otros las eximieron.

Antes de que se cumplieran los primeros seis meses del año, a inicios de mayo, Trump amenazó con incrementar las tarifas de 10\% — porcentaje que comenzó a aplicarse en 
septiembre de 2018 - a 25\% en productos con un valor de 200000 millones de dólares, lo cual comenzaría a regir desde el $1^{\circ}$ de enero.

A los pocos días, el 13 de mayo, los chinos respondieron con el incremento proporcional de tarifas a productos por un valor de 60000 millones de dólares. Los productos afectados fueron muebles, vegetales, aceite para cocinar, café, refrigeradores, carnes de res y cerdo, entre otros. Al mismo tiempo, exentaron temporalmente algunos productos que ya tenían aranceles y anunciaron que se podría imponer $25 \%$ de tarifas a productos como celulares y computadoras por un valor de 300000 millones de dólares. El $1^{\text {o }}$ de junio, además, China no solamente impuso aranceles de $25 \%$ a algunos productos, a otros les impuso $20 \%$, a unos más $10 \%$ y a otros $5 \%$.

Durante 2019 la relación bilateral alcanzó los puntos más bajos del conflicto iniciado por Donald Trump para revertir el déficit comercial. La llamada guerra comercial también se ha expresado en conflictos en torno a la reciprocidad en materia de servicios financieros y tecnología-seguridad nacional.

El arresto de Meng Wanzhou, ejecutiva de Huawei e hija de su fundador, Ren Zhengfei, en noviembre de 2018, cuando se dirigía a México, fue un momento de gran tensión. La disputa entre los gobiernos tomó un cariz personal y se tornó emotiva para los chinos. En mayo, la presidencia de los Estados Unidos renovó su lucha en contra de esta empresa china, agregándola, junto con sus filiales, a una lista de entidades a las que las empresas de telecomunicaciones no podían vender nada sin aprobación gubernamental. A las pocas semanas se agregaron a la lista empresas como Sugon, el Instituto de Tecnología de Computación Wuxi Jiangnan, Higon, Chengdu Haiguang de Circuitos Integrados y la Tecnología de Microelectrónicas Haiguang de Chengdu.

Las negociaciones bilaterales nunca cesaron totalmente. Las burocracias de alto nivel se reúnen o se comunican telefónicamente de manera regular. Llevan más de una decena de encuentros dentro del llamado Diálogo Económico Integral China-Estados Unidos y avanzan en propuestas. Sin embargo, Trump ha tratado de fijar la agenda y decide si llegan a acuerdos o no. Hay algunas concesiones de parte de los Estados Unidos pensadas para beneficiar prioritariamente a empresarios y consumidores antes que a los chinos. Tal es el caso posibilitar que compañías estadounidenses soliciten que algunos productos de origen chino 
sean exentados de las tarifas. Además, las sanciones que deberían aplicarse el $1^{\mathrm{o}}$ de septiembre fueron pospuestas hasta el 15 de diciembre, seguramente para no enfrentarse con los consumidores durante el Black Friday y con motivo de las compras navideñas. Incluso antes, a mediados del año, las sanciones en contra de Huawei fueron menos intensas.

Al mismo tiempo que anunció exentar 110 productos chinos, Trump amenazó una y otra vez con imponer tarifas hasta por 325000 millones de dólares. Xi siempre ha respondido en especie, como en junio, cuando su gobierno, por medio de la Comisión de Aranceles Aduaneros del Consejo de Estado, anunció la imposición de tarifas a 75000 millones de dólares, que corresponden a poco más de 5000 productos, a partir del $1^{\circ}$ de septiembre y del 15 de diciembre. Como ha sido la constante, los estadounidenses se enfocan en electrónicos y los chinos en productos agrícolas. Días antes de que entrara en vigor la medida estadounidense de mediados de diciembre, los chinos exentaron de tarifas a la soya y el cerdo, en respuesta a las decisiones de la Casa Blanca.

El enfrentamiento alrededor de Huawei es nimio frente al apoyo de varios actores políticos y económicos a la oposición en Hong Kong.

Empresas europeas y estadounidenses no pocas veces se vieron enfrentadas con el gobierno chino. Las segundas incluso con el gobierno de su país. El malestar chino estuvo relacionado con el hecho de que algunas compañías no presentan a Hong Kong, Taiwán y Tíbet como parte de China. La otra razón es el apoyo expresado a los movilizados políticamente en las calles de Hong Kong. El caso más sonado fue el de Daryl Morey, gerente general del equipo de baloncesto Rockets de Houston, quien tuiteó en favor de lo que él llamó la lucha por la libertad. En todos los casos, las empresas se disculparon inmediatamente con Beijing. Mike Pence (Rascoe, 2019), vicepresidente estadounidense, criticó duramente a la National Basquetball Assocation (NBA). Mientras que, según Pence, en su país ejercen cotidianamente la libertad, frente a China no lo hacen.

La parte más conflictiva del enfrentamiento está asociada a la firma presidencial de la S. 1838, denominada Acta de Derechos Humanos y Democracia de Hong Kong de 2019, convertida en ley a partir de una propuesta hecha en junio del mismo año. De acuerdo con la ley (Rubio, 2019), que reforma la S. 173 de 1992 que regía la política hacia Hong Kong, el Departamento de Estado informará anualmente al Congreso si la Región Administrativa 
Especial es lo "suficientemente" autónoma como para recibir un trato diferenciado, para lo cual se tomará en cuenta la situación de las libertades civiles y cómo afectaría la erosión de la mencionada autonomía la relación entre los Estados Unidos y la isla. Además, en el mismo lapso el Departamento de Comercio ha vigilado de cerca los esfuerzos que el continente pudiera hacer para utilizar a Hong Kong con el fin de evadir sanciones y controles a las exportaciones chinas.

Al dar a conocer la firma (Trump, 2019), la Casa Blanca precisó que la ley "pudiera" interferir con la autoridad presidencial para "establecer" la política exterior, por lo cual su administración tratará cada parte de la ley “consistentemente con los poderes constitucionales respecto a las relaciones exteriores". Además de decidir no enfrentarse a una decisión de un Congreso que se presentó inusualmente unido, signar el documento le permitirá a Trump ejercer mayor presión sobre Beijing, por el hecho de que la ley le mandata a sancionar a China; no obstante, ya hizo saber que hará lo que considere necesario de acuerdo con sus facultades presidenciales. Más que una ley, Trump tiene una herramienta de presión y negociación.

A inicios de 2020, el conflicto podría escalar. La Cámara de Representantes aprobó un proyecto de ley para castigar a China por su política respecto a los uigures de Xinjiang. La diferencia con la ley ya aprobada respecto a Hong Kong, además de la prohibición de exportar equipo que podría usarse para reprimir a la población, va dirigida en contra de funcionarios partidarios y gubernamentales, entre los que destaca Chen Quangao, principal dirigente de la Región Autónoma. La propuesta aún tiene que pasar por el Senado antes de que Trump decida firmarla o no, lo cual estará sujeto al estado de las negociaciones con Beijing en ese momento.

\section{Japón}

Se esperaba que el año terminaría con una visita de Abe Shinzo a China el 23 de diciembre, la cual sería respondida por un viaje de Xi a Tokio en algún momento de 2020. A la primera se sumaría Moon Jae-in, mandatario de Corea del Sur, a fin de continuar las negociaciones para limar las asperezas entre la península y la isla. Ya en agosto se habían reunido en Beijing los ministros de relaciones de los tres países: Wang Yi, anfitrión; Taro Kono, japonés; y Kang 
Kyung-wha por parte de Corea del Sur. Este conflicto ha puesto a Beijing en una posición de poder de la cual carecía, sobre todo porque buscará administrar el enfrentamiento a su favor, y los estadounidenses, que no se quedarán fuera, llegarán tarde al proceso. Además, está en su interés firmar un tratado trilateral de libre comercio en la región con Seúl y Tokio.

En la actualidad China es el principal socio comercial de Japón. Hacia ese país van USD \$144053 344744 en mercancías, y desde el continente se importan USD $\$ 173611807472$. En el rubro de exportaciones niponas a China, ésta ocupa un sitio ligeramente superior al de los Estados Unidos; porcentualmente la diferencia es de apenas $0.4 \%$, mientras que en cuanto a importaciones su lugar es indisputable, con una diferencia de USD \$90 040928782 . En porcentajes, China tiene 23\%, y Estados Unidos apenas 11.2\% (Global Edge, 2019a).

Los intercambios económicos y financieros entre ambas economías mantienen productos y servicios tradicionales, pero poco a poco los superan. Pese a que la guerra económica sino-americana afecta las transacciones China-Japón, los principales productos exportados por los nipones a China son los robots para usos productivos. Además, como parte de un proceso de liberalización de sus mercados de capital, desde mediados de 2019 existen cuatro fondos con USD \$218.3 millones, y gracias a sus acuerdos bilaterales de conectividad los inversionistas podrán negociar financieramente tanto en Tokio como en Shanghái.

Mientras que la simetría en su interdependencia económica se incrementó en los últimos meses y no parece tener otros límites que los impuestos por el proteccionismo estadounidense, otro asunto son la soberanía y la seguridad nacional. El tema central es la posesión y el uso de recursos, lo mismo espaciales que marítimos y del subsuelo, en el Mar del Sur de China.

En Tokio, algunos consideran (Akiyama, 2019) que todos los movimientos chinos, como el diseño de un código de conducta para los actores involucrados en la zona, están dirigidos a dejar fuera del juego a japoneses y estadounidenses, pero también a nulificar lo que los países del sureste de Asia puedan hacer para hacer valer sus reclamos. Si bien en el pasado las dos potencias de la zona llegaron a acuerdos para el uso de algunos recursos naturales, lo que predomina es el conflicto. Por una parte, Beijing continúa con sus proyectos de militarizar todo pedazo de tierra posible; Tokio, a su vez, de formas más limitadas, hace 
lo propio. Después de negociar con el propietario (Ryall, 2019), el gobierno japonés compró una isla de ocho kilómetros cuadrados, situada a 800 kilómetros de China y 32 de Japón, cerca de Okinawa. Igual que en la Segunda Guerra Mundial, la isla será utilizada para el aterrizaje de aviones de entrenamiento de las fuerzas de autodefensa japonesas.

\section{Corea del Sur}

La situación de los intercambios comerciales entre Seúl y Beijing es similar a la de este último con Japón: el socio principal no son los Estados Unidos. La diferencia es que el espacio entre el primer lugar, correspondiente a los chinos, y el segundo, a los estadounidenses, es abismal tanto en exportaciones como en importaciones (Global Edge, 2019b). Los coreanos exportan a sus vecinos USD \$162 124667 641, frente a lo que se vende al otro lado del Pacífico, que asciende a USD $\$ 73043815$ 673. En cuanto a importaciones, los chinos venden USD \$106487854094 y los estadounidenses solamente USD $\$ 59080559387$.

Al igual que Japón, la parte sur de la península es una economía de gran integración con China. Los principales productos importados desde China son (OEC, 2019): circuitos integrados, $10 \%$; equipo para radio y televisión, $5.1 \%$; partes para máquinas de oficina, $1.3 \%$; computadoras, 3.4\%; teléfonos, 2.6\%. Mientras que entre los principales productos exportados figuran circuitos integrados, $17 \%$; autos, 6.7\%; barcos de pasajeros y carga, 4.1\%; vehículos, 3.2\%.

Además de la contribución de China como mediadora del conflicto coreano-nipón, Seúl se ha acercado cada vez más a Beijing en los últimos meses conforme se incrementan la violencia verbal de Pyongyang y los roces con los Estados Unidos.

\section{Europa}

Históricamente las relaciones entre la Unión Europea (UE) y China se han conducido en el marco del Acuerdo de Comercio y Cooperación de 1985; posteriormente se firmó el Acuerdo de Asociación, 2007. En 2013 se negoció un documento de mayor complejidad y perspectiva (Unión Europea, 2013). De manera consistente, sobre todo a través del Alto Comisionado 
para Asuntos Exteriores y Política de Seguridad de la Comisión, la UE produce sus propios documentos coyunturales en los que analiza la relación con Beijing, como la Estrategia sobre China 2016.

En marzo del año pasado se publicó un documento (European Commission and High Representative of the Union for Foreign Affairs and Security Policy, 2019) que analiza y plantea cuáles deberían ser las políticas respecto a China. En el documento se reconoce a China como socio en materia de cooperación, con el cual se tienen objetivos comunes, y con el que se compite, por lo cual se requiere encontrar un equilibrio de intereses; es un competidor económico, sobre todo en la búsqueda del liderazgo tecnológico; y, finalmente, es un rival sistemático en cuanto a la promoción de modelos alternativos de gobernanza.

La propuesta aboga por un acercamiento diferenciado, flexible y pragmático, basado en la defensa de principios y valores. Sobre la base de lo anterior, se tendrían que

- profundizar sus compromisos para promover intereses comunes a nivel planetario,

- buscar formas más equilibradas y de condiciones recíprocas que gobiernen la relación económica,

- adaptarse a nuevas realidades económicas y fortalecer su economía, lo que les permitirá mantener su prosperidad, valores y modelo social.

A su vez, China mantiene una serie de políticas muy activas que se expresan en los viajes del presidente Xi Jinping. Las preocupaciones chinas son tres: lograr apoyos para la política "Un cinturón, un camino”, inversión y Huawei, que, aunque está ligado a lo segundo, tiene su propia dinámica. Sobresalieron los viajes de Xi a países como Italia y Francia.

En términos políticos, la visita de Xi a Francia durante el mes de marzo ha sido de una gran relevancia, ya que establecieron diversos acuerdos económicos, entre los que destaca la compra de 300 aviones a Airbus por alrededor de 28000 millones de euros. Políticamente lo sobresaliente fueron las reuniones sostenidas con Angela Merkel, canciller alemana; Jean-Claude Juncker, presidente de la Comisión Europea, y Emmanuelle Macron, mandatario francés. Mientras que los europeos insistieron en establecer reglas nuevas del juego, Xi se concentró en impulsar su política de la Nueva Ruta de la Seda, a la cual los europeos no se oponen, pero esperan reciprocidad en la apertura de mercados. 
Para la prensa china (Xinhua, 2019), lo relevante del viaje fue, primero, que los gobiernos francés e italiano se sumaron a la iniciativa "Un cinturón, un camino". La agencia Xinhua destaca el discurso de Xi sobre los cuatro déficits: gobernanza, confianza, paz y desarrollo, para cuya solución propuso cuatro enfoques: equidad y razonabilidad, consulta y comprensión, esfuerzos conjuntos y asistencia mutua, beneficio mutuo y resultados beneficiosos para todos.

Respecto a Huawei, el consenso informal europeo es contrario al sentimiento estadounidense de bloquear su avance en la red 5G. La postura francesa es no excluir a nadie de su mercado, donde operan Erickson, Nokia y la empresa china, que tiene $25 \%$ del mercado. De hecho, a finales de noviembre el organismo regulador francés, Autorité de Régulation des Communications Électroniques et des Postes (ARCEP), puso a la venta el espectro de la $5 \mathrm{G}$.

En China, a inicios de ese mes, Macron y Xi habían firmado acuerdos por valor de 15000 millones de dólares. Las empresas francesas Engie y Total trabajarán con contrapartes chinas, como Grupo Gas de Beijing, para construir un depósito de gas en Tianjin, y otro proyecto destinado a distribuir gas natural líquido, respectivamente. Además, los franceses exportarán cerdo, pollo y res, situándose como una opción a los productos estadunidenses.

China y Alemania, que intercambian alrededor de 200000 millones de euros anualmente, mantienen una asociación estratégica en un contexto de no pocos roces. Desde mediados de enero se supo que el gobierno alemán estaba discutiendo qué hacer respecto a Huawei y la red 5G, lo cual resolvió en octubre en favor de la participación de la empresa china en su mercado.

Las preocupaciones europeas tienen que ver, primero que nada, con derechos humanos, sobre todo con el tratamiento dado a la población uigur en Xinjiang. La disputa llegó a la Organización de las Naciones Unidas (ONU), presentándose ante el Alto Comisionado de Derechos Humanos y ante el Consejo de Derechos Humanos y la Asamblea General. Bajo el patrocinio de Gran Bretaña, 23 países apoyaron una resolución condenatoria de la política de Beijing en esa región autónoma china. Entre los Estados que apoyaron se encontraban Alemania, Australia, Austria, España, Estados Unidos, Francia, Irlanda, Islandia, Japón, Letonia, Suecia, Suiza, Países Bajos y Noruega. A éstos habría que agregar 
gobiernos. China mostró su poder diplomático y logró la firma de más países, entre ellos no pocos de población musulmana. Algunos de los firmantes fueron Angola, Argelia, Bielorrusia, Bolivia, Burkina Faso, Burundi, Camboya, Camerún, Congo, Cuba, Egipto, Emiratos Árabes Unidos, Eritrea, Gabón, Kuwait, Laos, Myanmar, Corea del Norte, Pakistán, Qatar, Rusia, Somalia, Sudán del Sur, Sudán, Siria, Tayikistán, Togo, Turkmenistán, Venezuela y Zimbabue.

Otro aspecto preocupante en la relación tiene que ver con la economía. Cada país tiene una agenda bilateral con Beijing en función de las necesidades de sus consumidores, pero sobre todo de sus empresas, además de preocupaciones específicas en materia de seguridad. En lo económico sobresale la inversión. Durante el año pasado un tema quedó pendiente: la firma de un Acuerdo Comprensivo sobre Inversión, que Beijing ve cerca y a los europeos no les apura, por lo menos no hasta 2020, cuya negociación inició en 2013. Las cifras confirman (Chen , 2019) que es necesario hacer algo para relanzar la inversión china. Durante 2019 habría ocurrido un descenso de la inversión de 84\%.

Para China, Inglaterra se ha convertido en el lugar más atractivo de Europa. Por ejemplo, cuando en 2018 en Alemania se reportó una inversión de apenas 500 millones de dólares, en Inglaterra ésta fue de 10000 millones de dólares. Detrás de estas negociaciones hay discusiones complejas sobre acceso a mercados, pero el verdadero problema es el tipo de desarrollo y su sustentabilidad.

El futuro de Gran Bretaña, sobre todo si finalmente se materializa el Brexit, se podría ligar más a China. Las posibilidades serían, para la primera, un alejamiento positivo respecto a Washington, colocándose en China, sin restricciones, lo que ya no entraría a Europa. Para los chinos, en cambio, la relativa debilidad británica, incluso solamente inglesa, los pondría en mejores condiciones de negociación que las logradas con los continentales. El único aspecto insalvable en las relaciones bilaterales es la posición de diversos actores británicos respecto a las movilizaciones sociales de Hong Kong, a propósito de las cuales la postura de Beijing es completamente no negociable.

Desde una perspectiva general, los europeos de la Unión se están acercando a China al tiempo que se alejan de Trump, no de los Estados Unidos. Las diferencias con él han llegado a lo risible. En lo económico, China y la UE lograron resolver diferencias 
sustanciales, aunque los conflictos continuarán. El punto crucial, el de la seguridad, enmarcada en el mecanismo institucional multinacional más importante existente, la OTAN, resultó un triunfo para China. En la Declaración de Londres (NATO, 2019), en la última parte del apartado sexto de nueve, se reconoce que la ascendente influencia china significa "tanto oportunidades como desafíos", que tendrán que ser abordados "juntos como Alianza”.

\section{México}

En abril se despidió de México Qiu Xiaoqi, posiblemente el embajador chino con mayor presencia pública que haya representado a su país en la capital mexicana hasta ese momento. Como un reconocimiento a su labor, el gobierno de Andrés Manuel López Obrador le entregó la Condecoración de la Orden Mexicana del Águila Azteca.

Su relevo, Zhu Qingqiao, llegó el 23 de abril. Salvo un corto paso por la política doméstica, en el periodo 2014-2017, cuando fue vicealcalde de Zhuhai, Guangdong, ha hecho su carrera en el mundo de la diplomacia, casi siempre ligado a la Dirección General de Relaciones Exteriores de América Latina y el Caribe del Ministerio de Relaciones Exteriores y al mundo lusófono, ya que fue diplomático en Mozambique y Brasil. En ese ministerio también cumplió funciones políticas entre 2003 y 2007, cuando fue director y consejero del Comité de Órgano del Partido.

Durante estos meses, el embajador Zhu, al igual que su antecesor, ha desplegado una amplia agenda. Publica textos en por lo menos tres periódicos de la Ciudad de México en los que expone la posición de su país respecto a la gobernanza o sobre la situación en Hong Kong, así como sobre políticas chinas relacionadas, por ejemplo, con la pobreza. Ha viajado a diferentes estados mexicanos para entrevistarse con gobernadores y con empresarios de Baja California, Puebla y Tabasco, entre otros. También se ha encontrado con funcionarios del gobierno federal, empezando con los de la Secretaría de Relaciones Exteriores (SRE) y de Economía (SE). Asimismo, ha sostenido encuentros con personajes que tienen un peso económico y político específico importante, como Carlos Slim y Jesús Seade, subsecretario de la SRE para América del Norte. 
Con el cambio de gobierno, las relaciones bilaterales caminan hacia la normalización, después de los desencuentros con Enrique Peña Nieto (2012-2018). El interés es explícito, mutuo y se fortalece. El primer signo del fortalecimiento de los lazos, como sucede con muchos países, es el interés mutuo, pero sobre todo las acciones chinas para que el turismo de ese país asiático a México se incremente. Aun cuando solamente $0.06 \%$ de los turistas chinos visitan México, el actual gobierno busca que de 170000 visitantes en 2019 se llegue a 214000 en 2024 (Reyna, 2019).

A mediados de año, Marcelo Ebrard, secretario de Relaciones Exteriores, viajó a Osaka para participar en la reunión del Grupo de los 20 (G20), donde logró tomarse una foto con el mandatario chino, Xi Jinping. Al final del evento se trasladó rápidamente a Beijing, para entrevistarse con el vicepresidente, Wang Qishan. El funcionario mexicano se mostró abierto a negociar una asociación estratégica integral y profundizar la cooperación, mientras Wang abogó por la cooperación pragmática. También se entrevistó con Wang Yi, consejero de Estado y ministro de Asuntos Exteriores, con quien se abordaron los mismos temas que con Wang, pero con énfasis en la necesidad de fortalecer el multilateralismo y la gobernanza global.

En materia de intercambios comerciales, a finales de noviembre de 2019 el déficit ascendía, todo en cantidades redondeadas, a -56 000 millones de dólares. La diferencia entre exportaciones, USD \$5 000, e importaciones, USD \$62 000 millones, confirma por un año más la situación existente desde, por lo menos, los años ochenta y que no ha cesado de crecer, como se ve en la gráfica 1 . Aun cuando las cifras chinas difieran de las locales, por ejemplo, cuando aseguran que en 2018 los intercambios fueron de 58000 millones de dólares, alrededor de 30000 millones de dólares menos de lo que aseguran las fuentes mexicanas, revertir la situación se antoja imposible. 
GRÁFICA 1. Intercambios comerciales México-China, 2015-2019

(miles de millones de dólares)

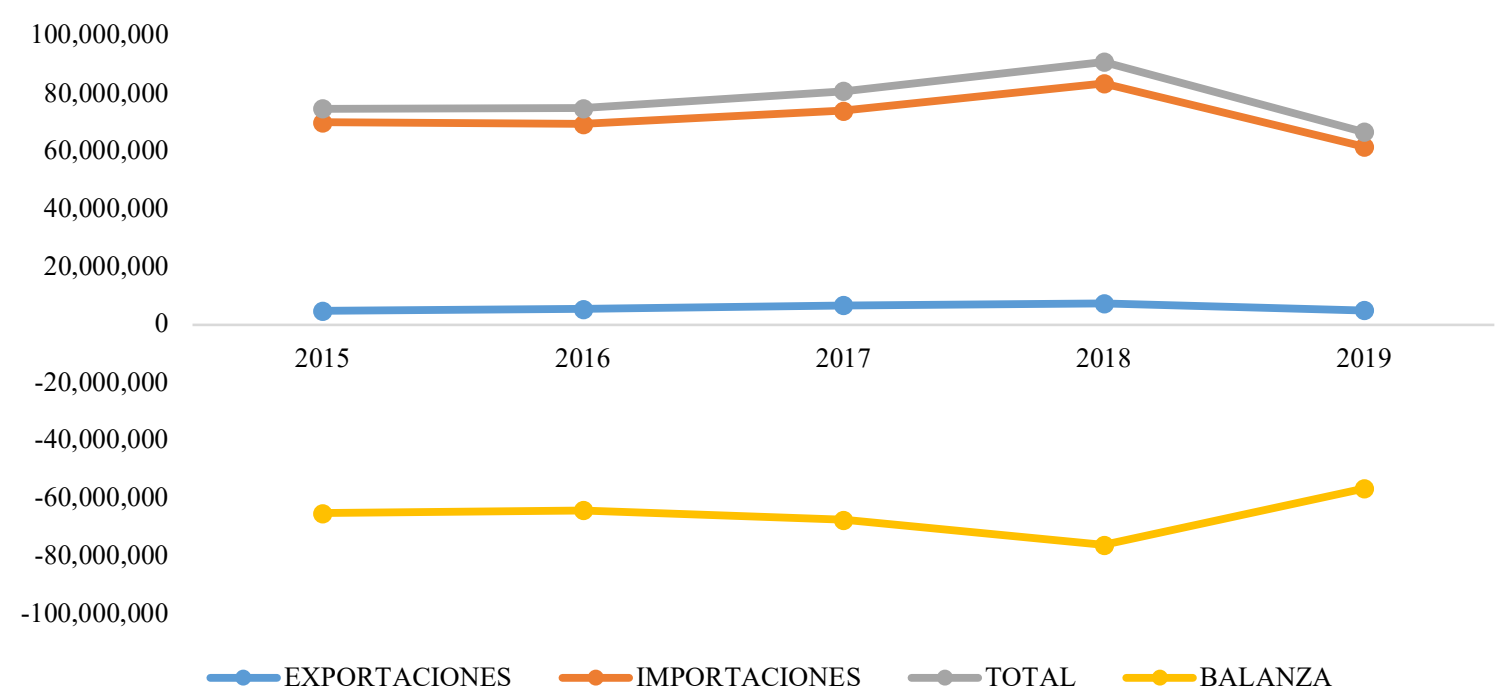

FUENTE: Secretaría de Economía (2019).

Si bien el gran objetivo de todos los embajadores chinos ha sido lograr un tratado de libre comercio, en términos de lo posible, la misión principal del nuevo embajador apunta a promover la inversión en infraestructura, por ejemplo, en el aeropuerto de Santa Lucía y el Tren Maya. Desde noviembre de 2018, Shanwen Xin, director general del Banco de China, expresó la disposición a financiar diferentes proyectos (Forbes, 2018).

Comparada con la inversión proveniente de otras economías asiáticas, históricamente la de China ha sido más bien pequeña. A noviembre de 2019, la inversión total general de China es de poco más de 1000 millones, frente a 871 millones de Singapur, 991 millones de Hong Kong, 1000 millones de Taiwán, más de 6000 millones de Corea del Sur, y en primer lugar Japón, con 25000 millones (todas las cifras en dólares estadounidenses). Desde 2008, la inversión china ha sido un sube y baja con alzas considerables; ese año la inversión llegó a los 33.4 millones. Y 2018 fue el de la mayor cantidad del periodo: 206 millones. En 2019 apenas se alcanzaron, a noviembre, 49.5 millones.

Los sectores atractivos para los chinos han sido, además de bienes y servicios, infraestructura, telecomunicaciones y minería. Los chinos han estado involucrados en ellos desde diferentes ángulos y aprecian ahí uno de los filones más productivos. De acuerdo con 
la Secretaría de Economía (Aristegui Noticias, 2019), en Bacadéhuachi, Sonora, existe el principal proyecto de desarrollo del litio del mundo. La parte complicada del proceso, además de la extracción, es la separación del litio de otros metales. Esta tarea estará a cargo de Ganfeng, una empresa china listada en las bolsas de Shenzhen y Hong Kong, integrada a este plan a partir de octubre de 2019. El proyecto, denominado Bacanora, está listado en Londres y busca obtener 300 millones de dólares al inicio de 2020. Su gobierno ha autorizado a Ganfeng para comprar una participación accionaria de $29.99 \%$ en Litio Bacanora y 22.5\% en Litio Sonora (Minería Pan-Americana, 2019).

Uno de los aspectos más cuidados por los chinos es el cultural. Además de las actividades que realizan las comunidades chinas, con mayor o menor apoyo de la embajada, existen otras. En 2019, por ejemplo, el China International Publishing Group donó un millar de libros a la Biblioteca México y cada año llegarán 200 obras. Asimismo, en agosto se inauguró en el Museo Nacional de las Culturas del Mundo la exposición Arte y paz. Obras contemporáneas chinas, y en diciembre, en el mismo recinto, la exposición digital La esencia espiritual del mundo.

A lo largo del año también hubo expresiones culturales de origen chino, pero no avaladas por el Beijing. Es el caso del espectáculo Shen Yun, que se presenta en varias ciudades mexicanas y es impulsado por Falun Dafa. Además, en la Universidad Nacional Autónoma de México, en el Museo de Arte Contemporáneo, se presentó una exposición de Ai Weiwei titulada Restablecer memorias, en la que el artista plantea su visión crítica de la historia china y la pone frente al espejo de los acontecimientos políticos, sobre todo ante los estudiantes de Ayotzinapa desaparecidos.

\section{Brasil}

Los chinos han tomado con parsimonia las declaraciones de Jair Bolsonaro respecto a ellos, sobre todo las de su campaña electoral. Para los chinos, el país sudamericano es clave por su peso regional y global, sobre todo en relación con el marco que les ha brindado el bloque de los BRICS, como veremos más adelante. Si bien comercialmente los intercambios con los brasileños son poco significativos para los chinos, con apenas $1.1 \%$ de lo exportado y $3.1 \%$ de lo importado, la relación es importante debido a productos específicos como la soya, y a 
su influencia política en América Latina, que a China le serviría para afianzarse en el continente y desafiar a los Estados.

Lo que parecía imposible ha pasado. Trump, argumentando manipulación monetaria por parte de brasileños y argentinos, anunció a finales de 2019 que impondría aranceles al aluminio y el acero procedentes de Brasil. La primera respuesta de Bolsonaro fue que, como no era una decisión, esperaba una rectificación.

Durante 2019, China se concentró en promover su política “Un cinturón, un camino", así como a alentar a los brasileños a que efectúen reformas legales en materia de impuestos, de pensiones y laborales. Asimismo, alentó a sus empresas, principalmente Didi, Tencent, AliExpress de Alibaba, y por supuesto Huawei.

APEC

Para Beijing, y también para Washington, la cumbre del Foro de Cooperación para AsiaPacífico (APEC), que debió celebrarse el 16 y 17 de noviembre en Santiago de Chile, pudo haber sido significativamente más importante en lo bilateral que en lo multilateral. Antes de que Sebastián Piñera, presidente chileno, decidiera suspender el evento anual más importante del organismo a finales de octubre, con el argumento de la seguridad debido a las movilizaciones sociales, se esperaba que Xi Jinping y Donald Trump firmaran un acuerdo que permitiera avanzar en las negociaciones comerciales.

Pese al incremento de las movilizaciones, Beijing apoyó a Piñera hasta el último momento, lo cual hace comprensible el enojo de los chinos ante la propuesta chilena de que la cumbre de APEC podría realizarse junto con los Estados Unidos, obviamente en alguna de sus ciudades. En Beijing esperan ser consultados sobre cómo y dónde realizar el encuentro posiblemente en enero de 2020.

Durante todo el año los chinos participaron en diferentes actividades relacionadas con APEC, algunas organizadas por ellos mismos. Sus funcionarios estuvieron en las tres Senior Officials' Meetings (SOM3), encuentros realizados para preparar la cumbre de los Líderes y cuyo último encuentro fue en Puerto Varas, Chile, el 30 de agosto. Todavía un par de días antes de las movilizaciones, iniciadas el 18 de octubre, los chinos participaron en una reunión 
de los ministros de finanzas, cuyo tema principal fue la posibilidad de firmar un acuerdo comercial. El gobierno también impulsó “APEC Voces del futuro", un programa para promover la participación y las propuestas de los jóvenes de sus economías miembros. En otro nivel, a mediados de julio se realizó en Hangzhou el Foro de CEO, bajo los auspicios del China Business Council.

\section{BRICS}

Si a nivel de líderes la reunión del APEC CEO no fructificó, pasó lo contrario en la reunión realizada en Brasil por los BRICS (Brasil, Rusia, India, China y Sudáfrica bajo el título BRICS: crecimiento económico para un futuro innovador). Tres elementos son destacables: el primero, la reagrupación del bloque, que parecía estar a punto de dispersarse debido a la política de Bolsonaro de mayor acercamiento con los Estados Unidos; en el mismo contexto, la tendencia sino-brasileña al acercamiento, que responde a las presiones de los exportadores brasileños para evitar el distanciamiento con los compradores chinos y su gobierno; además, Xi obtuvo una invitación de Narendra Modi, primer ministro, para visitar India en 2020. Importante, pero ya parte de la relación actual, fue el encuentro que Xi mantuvo con Vladímir Putin, mandatario ruso.

Xi (MFA, 2019) pronunció un discurso, "BRICS: crecimiento económico para un futuro innovador", en el que se comprometió a una mayor apertura de su país y una mayor cooperación con América Latina y África; también habló de la necesidad de evitar el proteccionismo. La parte medular de las ideas del mandatario chino es que el llamado BRICS Plus sirva para incrementar el diálogo y tener más socios.

\section{HONG KONG}

Sin duda, el acontecimiento más importante sucedido en Hong Kong durante 2019 fue la movilización social en contra de los gobiernos. Si bien los más activos y visibles han sido los estudiantes de prácticamente todos los niveles educativos, casi toda la sociedad ha expresado su descontento y se ha movilizado en diferentes momentos y formas. Hasta el 24 de noviembre y el 8 de diciembre ninguna de las partes estaba dispuesta a ceder ni siquiera un 
ápice. En el primer caso, se pospuso toda propuesta para ir a votar, y en el segundo, la policía concedió un permiso para realizar una manifestación, la cual congregó a unas 800000 personas que respondieron a la convocatoria del Frente Civil de Derechos Humanos.

Después de seis meses de protestas, el gobierno dice que tiene disposición a escuchar, aunque sin dar respuesta a las cinco demandas propuestas: retiro total de la propuesta de ley de extradición; formación de una comisión independiente para investigar la supuesta brutalidad policiaca; que no se etiquete a los manifestantes como amotinados; amnistía para todos los presos que participaron en alguna de las protestas, así como voto universal para el Consejo Legislativo y la jefatura del Ejecutivo.

El descontento inicial estalló debido a que en febrero los servicios de seguridad presentaron una propuesta de reforma a la ley de extradición, que haría posible mandar a presuntos criminales a China para ser juzgados de acuerdo con sus leyes, la Fugitive Offenders and Mutual Legal Assistance in Criminal Matters Legislation (Amendment). La ausencia de un tratado de extradición ha sido usada por personas que cometieron delitos de orden común, pero también por disidentes continentales que se han refugiado en Hong Kong.

Aunque se llegó a decir que la reforma era para mandar a Taiwán a Chan Tong-kai, quien asesinó a su novia embarazada, Poon Hiu-wing, la población interpretó la reforma como un intento para mandar a quienes son críticos del gobierno chino al continente para ser castigados en sus prisiones. De hecho, hay casos de opositores que han sido trasladados clandestinamente al continente para ser castigados.

El 31 de marzo miles de personas salieron a las calles a protestar. Pese a ello, Carrie Lam, quien está a cargo del Ejecutivo, decidió presentar la reforma ante el Consejo Legislativo. Pese a que la propuesta estaba destinada al fracaso, incluso algunos miles de abogados marcharon en junio en contra de la legislación propuesta; Lam se negaba a recular y luego fue ambigua, incluso cuando la pospuso en junio y la declaró muerta en julio. Durante seis meses las propuestas no han menguado. De hecho, el 23 de octubre la propuesta fue retirada formalmente por el gobierno, pero ya las partes en conflicto estaban en choque frontal por diferentes razones. 
Pese a la campaña electoral para los 18 consejos de distrito, la jornada del 24 de noviembre fue el único respiro que tuvieron los que protestan y las autoridades en medio año.

Bajo otro contexto estas elecciones hubieran sido intrascendentes. Esta parte de los procesos electorales no atrae grandes cantidades de votantes. Los electores no tienen ninguna influencia sobre los electos, a lo cual tendríamos que agregar que el sistema de elección es cada vez más indirecto y deja fuera de forma sistemática a algunos opositores, aun a pesar de la base social con la cual cuentan y de la legitimidad de sus ideas.

Inicialmente, casi todo el mundo mostró su satisfacción por los resultados de una elección que por momentos parecía que no se realizaría e incluso hubo intentos orientados a desalentar la participación, que alcanzó $71.2 \%$, sin que ocurrieran actos de violencia significativos ese día. Medios y funcionarios del continente no daban crédito a los resultados, los cuales no publicaron.

Beijing respondió de diferentes formas. Una mesurada fue un editorial institucional (China Daily, 2019) que, sobre la base del gran número de candidatos y de votantes, consideraba que quedó de manifiesto "la esperanza de los residentes de Hong Kong de que el caos no continuará, ya que está perjudicando el bienestar de las personas y la imagen de la ciudad como un lugar seguro para hacer negocios o para visitar”. Mientras tanto, gran parte de la prensa local — para no decir la obviedad de la editorialización de la extranjera—, así como los opositores, parciales o totales, al statu quo, se sintieron satisfechos con los resultados, que interpretan como un rechazo a Carrie Lam y a Beijing, pero también como un adelanto de lo que podrían ser los resultados de las elecciones para el Consejo Legislativo a celebrarse en septiembre de 2020. Una de las excepciones al optimismo compartido por polos opuestos fue Alice Mak (SCMP, 2019), de la Federación de Sindicatos, quien culpó de las derrotas de los candidatos oficialistas a la misma Carrie Lam por su deficiente gobernanza.

Las largas filas de gente ante las urnas, que llegó desde tempranas horas, es parte de un proceso heterogéneo en el que la población dice explícitamente a las élites políticas en el poder que desea mayor participación y una relación diferente con Beijing. Diferentes grupos sociales - los más visibles han sido los jóvenes — se han expresado a través del voto y de la 
protesta en las calles en múltiples ocasiones, y en esta oportunidad el detonador fue un acontecimiento que, aparentemente, no tocaba la vida de la población.

A lo largo de estos meses de protesta, Beijing y los políticos locales pro statu quo han movilizado a sus bases sociales en espejo con las acciones de los opositores. Su apoyo social se moviliza, marcha, canta, agita banderas, concede entrevistas, visita organizaciones internacionales y va a votar. Ya alejados de la mesura inicial, unos 1000 simpatizantes se movilizaron a inicios de diciembre para pedir un recuento de los votos de las elecciones de noviembre. La Comisión de Asuntos Electorales rechazó la solicitud.

El 18 de noviembre terminó el mandato de Stephen Lo a cargo de la policía local y fue sustituido por Chris Tang. Su llegada puede ser interpretada de formas mutuamente excluyentes; lo que sabemos hasta ahora es que permitió la marcha del 8 de diciembre y, según su versión (Leung y Lee, 2019), informó a Zhang Xiaoming, jefe de la Oficina de Asuntos para Hong Kong y Macao del Consejo de Estado, y a Zhao Kezhi, ministro de Seguridad Pública, que corresponde a la policía de la isla su propia seguridad; asimismo, negó explícitamente que el Ejército Popular de Liberación se vaya a inmiscuir. Además, explicó la combinación de tácticas que usarán para enfrentar las protestas y el endurecimiento a los que realicen actos ilegales.

Hay dos elementos históricos importantes para analizar estos movimientos y la actitud de Beijing. El primero de ellos es el origen de la situación política actual de la ex colonia británica. La zona de Hong Kong fue utilizada, junto a otros puertos, por el Imperio británico, con el propósito de comerciar el té de China de alta demanda en Gran Bretaña. Dado que al principio este producto era pagado en plata, lo que no convenía a las arcas del Imperio, los comerciantes británicos comenzaron a introducir opio al imperio chino para intercambiarlo por el té, lo cual estaba prohibido, y las autoridades locales realizaron confiscaciones de la droga; esto dio como resultado el estallido de la Primera Guerra del Opio. Los británicos derrotaron la desordenada respuesta del gobierno de la dinastía Qing, en plena descomposición por razones internas. De esa manera el Imperio chino cedió Hong Kong al Imperio británico en 1842, a través del Tratado de Nanjing, uno de los llamados tratados desiguales que las potencias obligaron al decadente imperio Qing a firmar a cambio de múltiples concesiones. Hong Kong se convirtió en colonia británica. 
En una Segunda Guerra del Opio, China fue obligada a ceder Kowloon, en 1860, y los llamados Nuevos Territorios por un lapso de 99 años, en 1898. En 1984 la primera ministra, Margaret Tatcher, firmó con el gobierno chino la Declaración Conjunta SinoBritánica y la devolución del territorio se hizo efectiva el $1^{\circ}$ de julio de 1997, cuando Hong Kong retornó definitivamente a la soberanía de China y se adoptó la Ley Básica de Hong Kong. La colonia había sido gobernada por un funcionario nombrado desde Londres, sin derechos políticos y con la prohibición explícita de permitir la existencia de un Partido Comunista. En sus últimos años como colonia británica hubo reformas que buscaban que las instituciones funcionaran como contrapeso al gobierno de Beijing.

Para el gobierno de China es importante recordar el significado político que en el Tratado de Nanjing marca el inicio de lo que la historiografía y la autopercepción política han llamado el "siglo de las humillaciones", elemento central en la construcción del nacionalismo hecha por el Partido Comunista.

El segundo elemento histórico que es necesario tener en cuenta es que Hong Kong fue un centro importante de concentración de todo tipo de agencias y organizaciones anticomunistas durante la Guerra Fría, que funcionaban para la contención del poder de China y de la Unión Soviética en la región. Muchas de estas organizaciones y centros de espionaje todavía funcionan en Hong Kong, varias convertidas en ONG, y colaboran estrechamente con algunos de los grupos disidentes en la Región Administrativa Especial. Su participación en varios movimientos anti-Beijing de los últimos años ha sido importante.

A su vez, es necesario explicar que el origen de las manifestaciones tiene que ver con la estructura de la población, en la que predominan jóvenes y personas de edades medias, cuyos ingresos se han visto tremendamente disminuidos por la competencia de Shenzhen y otros enclaves en la región. Además, se trata de una población educada, cuyas expectativas de trabajo son muy oscuras dada la mecanización y la consecuente disminución de personal en las empresas e instituciones bancarias ocasionada por el uso de internet.

Explicar las manifestaciones como una lucha por algo denominado democracia es una simplificación de los asuntos. Hong Kong mantiene muchas libertades individuales, de manifestación, de organización, de expresión, de comunicación, de publicación, que China ha mantenido como un ejemplo de lo que podría ofrecer a Taiwán. Pero Beijing no cederá a 
una independencia completa, no sólo porque sería un síntoma de debilidad en estos momentos en que se posiciona como una de las potencias más poderosas del mundo, sino también por lo que representa para su nacionalismo y porque es símbolo del ya mencionado "siglo de las humillaciones". También hay que considerar que no es gratuito que el movimiento estalle en medio de la guerra comercial con los Estados Unidos, y que la prensa internacional le dé más cobertura que a la represión en Chile, donde se calcula que la policía lesionó los ojos a cerca de 200 personas por protestas políticas.

El año finalizó tablas. Ninguna de las fuerzas está dispuesta a otorgar concesiones. La tendencia dominante ha sido la radicalización y la obstinación. El movimiento social local se internacionalizó al implicar al gobierno de Taiwán por aspectos legales, luego por los viajes de algunos dirigentes en el extranjero y por buscar apoyo en representaciones diplomáticas en Hong Kong. En diferentes lugares del mundo, políticos y activistas se han pronunciado en contra de Beijing. Pero lo que más ha irritado a esta capital es lo que ellos llaman la intromisión británica, y sobre todo la estadounidense, de la cual ya hemos hablado arriba.

\section{CONSIDERACIONES FINALES}

Los meses de 2019 se han caracterizado por algunos aspectos. Primero, la capacidad de Xi Jinping de afianzarse en el poder, con posibilidades de mantenerse en él tanto tiempo como sea necesario sin enfrentar, ni dentro del Estado-partido ni en la sociedad, una oposición que ponga en duda su dominio y con la suficiente fuerza para sacarlo del poder. Segundo, hasta ahora el mismo Xi y su equipo han contado con la capacidad de mantener el barco de la economía no solamente a flote; los elementos esenciales se mantienen en forma y con perspectivas de crecimiento de un modesto $6 \%$ comparado con los dos dígitos del pasado. Ante los conflictos en la región se erige como un líder capaz de resolver problemas, como ocurrió en el caso del enfrentamiento entre Corea y Japón a lo largo de casi todo el año. Tercero, lo anterior no quiere decir que no tenga roces con sus vecinos, que existen sobre todo alrededor de su expansión en el Mar del Sur de China. Cuarto, a nivel planetario, los chinos continúan fortaleciendo sus relaciones y ampliando sus mercados, a veces con la ayuda del mismo Trump, que aleja a sus aliados y los acerca a Beijing, como es el caso de 
Brasil y la misma Unión Europea. Quinto, tiene una política global, la de "Un cinturón, un camino", pero apenas es un proyecto en construcción. Sexto, el gobierno central chino ha logrado mantenerse a una distancia prudente de Hong Kong, aunque dejando claro en todo momento que la Región Administrativa Especial es parte integral de la República Popular China.

\section{REFERENCIAS}

Akiyama, H. (28 de noviembre de 2019). "Beijing turns South China Sea code into barrier for US and Japan". Recuperado el $1^{\circ}$ de diciembre de 2019 de Nikkei Asian Review: https://asia.nikkei.com/Politics/International-relations/Beijing-turns-South-China$\underline{\text { Sea-code-into-barrier-for-US-and-Japan }}$

Aristegui Noticias (6 de diciembre de 2019). "Yacimiento en Sonora, el principal proyecto en desarrollo de litio en el mundo: Francisco José Quiroga”. Recuperado el 6 de diciembre de 2019 de Aristegui Noticias: https://aristeguinoticias.com/0612/mexico/ yacimiento-en-sonora-el-principal-proyecto-en-desarrollo-de-litio-en-el-mundofrancisco-jose-quiroga/

Chen, W. (15 de agosto de 2019). “Chinese investment in Europe dips in H1”. Recuperado el 15 agosto de 2019 de China Daily: https:/www.chinadaily.com.cn/a/201908/ 15/WS5d54b008a310cf3e35565d68.html

China Daily (24 de noviembre de 2019). "HK district elections chance to step back from the brink of abyss", editorial. Recuperado el 24 noviembre de 2019 de China Daily: https://www.chinadaily.com.cn/a/201911/24/WS5dda880ea310cf3e355798e6.html

CNBC (7 de diciembre de 2019). "China's November foreign exchange reserves fall more than expected amid focus on trade deal'. Recuperado el 7 de diciembre de 2019 de CNBC: https://www.cnbc.com/2019/12/07/chinas-november-foreign-exchange-reser ves-fall-more-than-expected-amid-trade-deal-negotiations.html

European Commission and High Representative of the Union for Foreign Affairs and Security Policy (12 de marzo de 2019). "EU-China-A strategic outlook". 
Estrasburgo, Austria. Disponible en https://ec.europa.eu/commission/sites/betapolitical/files/communication-eu-china-a-strategic-outlook.pdf

Forbes (29 de noviembre de 2018). "Bank of China México quiere financiar infraestructura con nuevo gobierno". Recuperado el 5 de febrero de 2019 de Forbes México: https://www.forbes.com.mx/bank-of-china-mexico-quiere-financiar-infraestructuracon-nuevo-gobierno/

Global Edge (noviembre de 2019a). "Japan: Trade Statistics”. Recuperado el 5 de diciembre de 2019 de Global Edge: https://globaledge.msu.edu/countries/japan/tradestats

Global Edge (5 de diciembre de 2019b). "South Korea: Trade Statistics”. Recuperado el 5 de diciembre de 2019 de Global Edge: https:/globaledge.msu.edu/countries/southkorea/tradestats

Leung, C., y Lee, A. (7 de diciembre de 2019). "New Hong Kong police chief Chris Tang tells top Beijing officials that 'hard and soft' tactics will be used to thwart protest crisis”. Recuperado el 7 de diciembre de 2019 de South China Morning Post: https://www.scmp.com/news/hong-kong/law-and-crime/article/3041102/new-hongkong-police-chief-chris-tang-tells-top

Minería Pan-Americana (15 de octubre de 2019). "Ganfeng Lithium ingresa en el proyecto de litio Sonora, en México". Recuperado el 20 de octubre de 2019 de Minería Panamericana: https://www.mineria-pa.com/noticias/ganfeng-lithium-ingresa-en-elproyecto-de-litio-sonora-en-mexico/

MFA (15 de noviembre de 2019). "Xi Jinping Attends the 11th BRICS Summit and Delivers an Important Speech". Recuperado de Ministry of Foreign Affairs of the People's Republic of China: https://www.fmprc.gov.cn/mfa_eng/zxxx_662805/t1716898. $\underline{\text { shtml }}$

National Bureau of Statistics of China (25 de noviembre de 2019). "Statistics Database". Recuperado el 25 de noviembre de 2019 de National Bureau of Statistics of China: http://www.stats.gov.cn/english/Statisticaldata/AnnualData/ 
NATO (4 de diciembre de 2019). "London Declaration". Recuperado el 4 de diciembre de 2019 de North Atlantic Treaty Organization: https:/www.nato.int/cps/en/natohq/ official texts 171584 .htm

OEC (2 de diciembre de 2019). "South Korea". Recuperado el 2 de diciembre de 2019 de The Observatory of Economic Complexity: https://oec.world/en/profile/country/kor/

Panayiotides, N. (7 de noviembre de 2019). "Turbulence in global political economy". Recuperado el 8 de noviembre de 2019 de Asia Times: https://www.asiatimes.com/ 2019/11/opinion/turbulence-in-global-political-economy/

Rascoe, A. (24 de octubre de 2019). "Pence Chides NBA, Nike For 'Losing Their Voices' On China". Recuperado de National Public Radio: https://www.npr.org/2019/10/ 24/773025664/pence-chides-nba-nike-for-losing-their-voices-on-china

Reyna, J. (2 de diciembe de 2019). "México, destino favorito para turismo chino: Sectur". Recuperado el 2 de diciembre de 2019 de La Jornada: $\underline{\text { https://www.jornada.com.mx/ }}$ ultimas/economia/2019/12/02/mexico-destino-favorito-para-turismo-chino-sectur$\underline{5537 . h t m l}$

Rubio, M. (13 de junio de 2019). "Hong Kong Human Rights and Democracy Act of 2019”. Recuperado de Congress.gov: https://www.congress.gov/bill/116th-congress/senate$\underline{\text { bill } / 1838}$

Ryall, J. (2 de diciembre de 2019). "Japan buys Mageshima island for US\$146 million to conduct military drills with US". Recuperado el 2 de diciembre de 2019 de South China Morning Post: https://www.scmp.com/news/asia/east-asia/article/3040229/ japan-buys-mageshima-island-us146-million-conduct-military

SCMP (24 de noviembre de 2019). "Hong Kong elections: defeated lawmaker Alice Mak blames city leader for poll drubbing”. Recuperado el 24 noviembre de 2019 de Line Today: https://today.line.me/ID/pc/article/VGwxgB

Secretaría de Economía (25 de noviembre de 2019). "Sistema de Consulta de Información Estadística por País". Recuperado el 25 de noviembe de 2019 de http://www. economia-snci.gob.mx/sic php/pages/estadisticas/ 
Silver, L., Devlin, K., y Huang, C. (5 de diciembre de 2019). "People around the globe are divided in their opinions of China". Recuperado el 5 de diciembre de 2019 de Pew Research Center/Facttank. News in the Numbers: https://www.pewresearch.org/facttank/2019/12/05/people-around-the-globe-are-divided-in-their-opinions-of-china/

Trump, D. (27 de noviembre de 2019). "Statement by the President". Recuperado el 27 noviembre de 2019 de The White House: https://www.whitehouse.gov/briefingsstatements/statement-by-the-president-30/

Unión Europea (2013). "EU-China 2020 Strategic Agenda for Cooperation". Recuperado en enero de 2019 de European External Action Service: http://eeas.europa.eu/ archives/docs/china/docs/eu-china_2020_strategic_agenda_en.pdf

Xinhua (27 de marzo de 2019). "Xi's fruitful visits boost partnership with Europe". Recuperado el 27 de marzo de 2019 de China Daily: http://www.chinadaily. com.cn/a/201903/27/WS5c9b74a6a3104842260b2ef2_2.html 